\title{
Functioning of the person in crisis
}

\begin{abstract}
This article describes the conditions of preservation of the ability to the positive functioning of boys and girls in crisis situations. The presented research is built within the paradigm "salutogenesis", according to which the conditions of preservation of the physical and psychological health of the individual is an active, healthy focus on life goals, selfactualization, and not merely the absence of disease.
\end{abstract}

Keywords: crisis situation, experience, psychological well-being, positive functioning, methodological triangulation
Volume 9 Issue 4 - 2018

\section{Novak Natalya Gennadievna, Zhuravleva Alina Evgenievna}

Department of Social and Pedagogical Psychology, Gomel State University, UK

Correspondence: Novak Natalya Gennadievna, Department of Social and Pedagogical Psychology, Gomel State University, Europe, UK, Tel 375297312580 ,

Email natalya_novak_80@mail.ru

Received: July 28, 2016 | Published: August 21, 2018

\section{Opinion}

Within the modern health psychology concept of well-being (wellbeing) is widely used by researchers to determine the quality of life and health of the individual. Well-being - is a multifactorial construct, suggesting the influence of the system of cultural, social, psychological, physical, economic and spiritual factors. This sophisticated product the result of the influence of genetic predisposition, environment, and the features of individual development. According to the concept of $\mathrm{K}$. Riff, psychological well-being includes the following components: self-acceptance, and lived the life segment; meaningfulness of life, the presence of the objectives; social competence; the desire for self-realization and self-improvement; the ability to generate positive trusting relationships with others; capacity for autonomy and independence of judgment. ${ }^{1}$

psychological well-being indicators reflect the positive aspects of functioning of the individual: a positive attitude towards themselves and their past; awareness and acceptance of the different sides of the self; a sense of satisfaction from the warm, trusting relationships with others; concern for the welfare of others; capacity for empathy; selfdetermination and independence; the ability to resist social pressure, independence of judgment; self-regulation behavior; competence; self-realization; the presence of life goals and beliefs, the meaning of life; sense of the meaningfulness of their past and present; openness to new experience; prospects for personal and professional growth; self-knowledge and self-efficacy. The purpose of the study - based on a retrospective analysis of the experience of experiences highlight the social and psychological conditions of the positive functioning of the individual in a crisis situation. As mMETHODS study used a questionnaire "The scales of psychological well-being" of K. Riff adaptation NN Lepeshinsky ${ }^{2}$ and developed in accordance with the purpose of the study semi-structured interview.

The empirical sample included 415 boys and girls, 188 of which have experienced a crisis event. It was found that respondents with a level of psychological well-being "above the norm" greater among boys and girls, who have an experience of crisis events, compared with boys and girls who do not have this kind of experience $(21.8 \%$ and $13.6 \%$, respectively; $\varphi^{*} \mathrm{EMF}=2.17 ; \mathrm{p} \geq 0,05$ ). Boys who survived crisis event, compared with young men who do not have this type of experience, often have a high $\left(\varphi^{*} \mathrm{EMF}=1.983 ; \mathrm{p} \geq 0,05\right)$ and less low $\left(\varphi^{*} E M F=1.87 ; p \geq 0,05\right)$ level psychological well-being. With increase in the number of critical events increases psychological wellbeing index scale "Personal Development" (M1=5.38; M2=6.11; temp=2.1 at tcr $=1.97 ; \mathrm{p}=0.04)$. Consequently, In order to identify individual psychological wellbeing conditions used in crisis situations methodological triangulation data. ${ }^{3}$ It is possible to compare indicators of psychological well-being of the respondents with the content of the experience acquired experience of the crisis event. The study design was a comparative analysis of 120 cases. $^{3}$

Among the social conditions were classified as parental family structure (the presence of adoptive parents in the case of departure or death of the biological, the presence of siblings), the nature of relationships in the family of origin (conflicts between family members, exposure to psychological and / or physical violence in the family), the reason for a family member's death alcoholism parent. Group psychological (internal, subjective) conditions includes attitude towards himself and his own life (assessment of themselves as individuals, evaluation of himself as the subject of interpersonal interaction, assessment of their physical appearance, quality assessment of intra interaction, assessment of the degree of selfrealization in the relevant areas, the assessment lived stage of life), an estimation of the family system, the locus of the blame for what happened crisis event, having a goal in life, a way to overcome the difficulties of life.

The data obtained allow us to say that in a crisis situation, a person needs to restore a sense of direction, the meaningfulness of life. We need to create/strengthen the conviction that promote awareness of the purpose of life in the present, to raise the level of competence in environment management, which will allow a greater degree of control over external activities, effective use possible, to capture or create the conditions and circumstances are suitable to meet the personal needs and goals. The greatest value of a person's ability to function positively after experiencing a crisis events have developed a system of relations, a sense of meaning of life, the ability to plan their own lives (time perspective), as well as ways of coping with life's difficulties. Timely crisis intervention on the part of experts, taking into account the selected conditions will allow the person in crisis to structure and to significantly increase the degree of meaningfulness acquired in the course of the experience of individual experience. ${ }^{4,5}$

\section{Acknowledgements}

None. 


\section{Conflict of interest}

Author declares that there is no conflict of interest.

\section{References}

1. RyffCD, Keyes CLM. The structure of psychological well-being revisited. Journal of Personality and Social Psychology. 1995;69(4):719-727.

2. Pergamenshchikov LA, Lepeshinskii NN. Questionnaire. The scales of psychological well-being of K. Riff: process and adaptation procedure. psychol diagnostics. 2007;3S:73-96.
3. Paulien C. For Multi-method triangulation in a qualitative study on teachers' practical knowledge: an attempt to increase internal validity meijer, nico verloop and douwe beijaard. Quality \& Quantity. 2002;36(2):145-167.

4. Pergamenshchikov LA, Novak NG. Methodological triangulation as a way of constructing psychological research. Ineating. Brest. Filologiya sulfur. Pedagogika Psihalogiya. 2015;2:138-143.

5. Pergamenshchikov LA, Novak N. Socio-psychological conditions of psychological well-being of the person that has suffered a crisis event. Sots Psychology and Society. 2015;6(4):161-169. 